\title{
Analysis of the Similarities and Differences Between Chinese and Russian Ice-snow Oil Painting Art*
}

\author{
Lei Song \\ Heihe University \\ Heihe, China 164300
}

\begin{abstract}
The ambulant school" period at the end of the 19th century was the heyday of the development and innovation of Russian Ice-snow Oil Painting art techniques. Looking through the masterpieces of the Ice-snow Oil Paintings of various periods of Russian art, people can feel the fine art of Ice-snow Oil Painting techniques. The art of Russian Ice-snow Oil Painting has a unique and lofty position in the history of world art. The art techniques of Chinese Ice-snow Oil Painting are mainly based on the elements of "Chinese painting" and also draw on the development of Ice-snow Oil Painting techniques in many western countries. In today's China, the art of Ice-snow Oil Painting is continuing in the development direction of combining Chinese and Western. The promotion and interaction of the comparative research on the art techniques of SinoRussian Oil Painting and the promotion of Sino-Russian art exchanges and cooperation have become important research topics.
\end{abstract}

Keywords-Sino-Russian Ice-snow; oil painting art; similarities and differences of techniques

\section{INTRODUCTION}

Ice-snow Oil Painting art and technique language is a special visual expression means of "ice and snow" visual art. It uses lines, colors, light, structure and other painting languages to express the expression means and artistic methods of Chinese and Russian for the artistic creation of Ice-snow Oil Painting and discover the different creative techniques, language expressions, and innovative features of the art of Icesnow Oil Painting.

\section{APPLICATION AND PERFORMANCE OF SINO-RUSSIAN ICE-SNOW OIL PAINTING ART COMPOSITION SKILLS}

The basic task of Sino-Russian Ice-snow Oil Painting art is to clarify the idea of Ice-snow Oil Painting artists to the greatest extent. The Chinese and Russian Ice-snow Oil painters are most concerned about the artistic effect of a work. The purpose of composition is to express the ice and snow theme to achieve a concrete and perfect form structure to enhance the effect of Ice-snow Oil Painting art. If the composition is graphical, monotonous, and mediocre, although the snow and ice are prominent in the middle of the frame, it is still an unclear, boring, artistically inconspicuous composition.

*This article is a youth project of the Heilongjiang Philosophy and Social Sciences Research Plan, "Comparative Study of Sino-Russian Ice-snow Oil Painting Art Creation" project number: 16YSC01.
Therefore, it is impossible to make the work interesting and pleasing. The artistic effect of painting as a visual art depends on the artist's eyesight. If the artist's understanding of things is not deep, one-sided, superficial, the artistic quality of the Icesnow Oil Painting will be low. The poetry of the Ice-snow Oil Painting is always filled in the artistic image it creates, so it can quietly open the door of people's hearts. The artistic effect of the composition of Ice-snow Oil Painting depends on whether the painter discovers and feels the abstract visual beauty and the ability to deal with them from this theme. Because only after the artist's treatment, the audience can see what the artist has seen, and stimulate the same emotional resonance with the ice artist. Artists should be good at observing the visual elements inside the ice and snow theme. When we look at the concrete objects in winter life-people, tree houses, or ice flowers-their general characteristics should be removed, and they should be seen as a combination of form, line, texture, light and dark, color, and three-dimensional objects. Only the Ice-snow Oil painter vividly expresses the shape, color, texture, stereoscopic sensation, dynamic and spatial relationship of the object of painting through various styling means, so that it conforms to people's visual laws and truly feels for the viewer to achieve a satisfactory visual effect. If the Ice-snow Oil painter combines his inner imagination with skillful techniques, he will be able to obtain a beautiful and moving composition. The composition design must be beautiful, that is to say, it must be aesthetically pleasing, which is obviously clear.

\section{BASIC VISUAL ELEMENTS AND FORMS IN THE ARTISTIC CREATION OF SINO-RUSSIAN ICE-SNOW OIL PAINTING}

Sino-Russian Ice-snow Oil Painting relies on styling, color, and various visual painting factors. Ice-snow Oil painters combine these factors to create the works that people admired, touched and inspired.

Sino-Russian Ice-snow Oil Painting artists must not only have a creative intention, but also express this intention in a unique and interesting way. Therefore, the Ice-snow Oil Painting art composition method itself is very meaningful. Sometimes people tend to confuse the role of visual elements with the principles of composition. The visual elements are lines, colors, shapes and textures; the composition principle of Sino-Russian Ice-snow Oil Painting is proportional, balanced, contrast, rhythm, diverse and so on. It is the Ice-snow Oil Painting artist who combines the scattered parts into a 
complete picture to attract and capture the attention of the viewers.

The basic visual element of Sino-Russian Ice-snow Oil Painting art composition is the form, which can be divided into two types: the form of concept and the form of reality. The form in our experience system is the actual shape that can be seen or touched, which can be transformed into modeling elements. In addition, there are shapes that cannot be directly perceived by vision and touch, and are considered to be abstract forms or conceptual forms. The form of the concept cannot be directly perceived, so as a modeling element, it must be visualized to make it visible. In this form, we call it an abstract form or a pure form. Like geometry, pure form is based on points, lines, faces, and solids. The position and size of the point, according to such a point to define the movement, we can get the line, the surface, the stereoscopic sensation. Pure form, as a conceptual form, is always opposite to the real form, but at the same time it is the basis of all forms. As the basis of the basic form, it must be the opposite of most forms, but at the same time it is the basis of all forms. As a basic form, it must be a unit or a morphological element coexisting in most forms, and a pure form is exactly a form left after various attributes of reality forms. In fact, the realistic forms and modeling works made by human beings can of course be not limited to the basic forms and combinations of pure forms found in natural objects and natural phenomena. Therefore, it can be said that pure forms are the constituent elements and preliminary expressions of real forms.

\section{THE EXPRESSION OF "RHYTHM" IN THE ARTISTIC CREATION OF SINO-RUSSIAN ICE-SNOW OIL PAINTING}

Rhythm is an orderly process that provides a reliable pattern and pace. Once a certain rhythm is established, we can foresee its continuous appearance. Keeping the rhythm, we will feel happy.

Every aspect of our life and work is based on rhythm or obedience to the rhythm. It even becomes the power to control the interrelationships between various objects in nature. We have a rhythm of alternating around the clock, the four seasons, the waves, the heart beat, and we feel very harmonious. Light, heat, sound, and magnetism are all different forms of rhythm, and slight changes in them can lead to large differences. Every activity of a person is related to a certain form of rhythm. The gait of walking, the swing of the two arms, the symmetrical inclination of the shoulders and hips, and the twisting of the spine all have obvious rhythms. People of different ages and genders have different rhythms.

For music, rhythm is an extremely important factor. There are also many cases in the modeling works without time elements that recognize the rhythm as a repeated form and structure, such as continuous lines in the creation of Ice-snow Oil Paintings, intermittent lines, black and white intervals, repeated appearances and tones, and so on. Even if it is a static ice and snow creation, the change of the line of sight must be traced to the arrangement of the lines, shapes and morphological elements. It can be said that in the artistic creation of Ice-snow Oil Painting, the movement of the line of sight in time is the rhythm that people feel. All shapes must contain elements of the rhythm. For example, the natural phenomenon of winter ice and snow (the line of the mountains, the outline of the forest, the position of the trees, the flow of the glaciers, etc.) is the rhythm of space and time. In the creation of Sino-Russian Ice-snow Oil Painting, the coordination and arrangement of lines, shapes, colors, light, and orderly composition are repeated, resulting in the feelings of rhythm. The strength and length of the line, the strength of the color and the size of the area, the amount of pigment, etc., all the techniques of Sino-Russian Ice-snow Oil Painting creation are related to the rhythm. Therefore, rhythm is one of the indispensable conditions in shape performance. Rhythm is one of the aesthetically significant conditions of natural phenomena. The rhythm can sometimes be generalized as a special means of expression, sometimes with direct descriptive meaning, but without an art, the rhythm does not play a role in it.

\section{THE Role of COLOR TECHNIQUES IN THE ARTISTIC CREATION OF SINO-RUSSIAN ICE-SNOW OIL PAINTING}

The color composition of Ice-snow Oil Painting art works has a great effect on the composition. It is a very powerful means to attract, stimulate and influence the audience's feelings and enhance the performance of Ice-snow Oil Painting art works. The discoloration of color can give people a feeling of change and harmony; the strong contrast gives people a distinct and eye-catching feeling. Not only that, the shapes expressed in the artistic creation of Sino-Russian Ice-snow Oil Painting do not depend solely on them. Contours, ridges, and extension of the axis, etc., also depend on the relationship between hue and color. For example, when the basic color of the object is brighter and warmer for the background, it appears to expand outward, and when the relationship is reversed, it will produce a reduction effect. (1) The color has a sense of direction, color with strong the luminosity and the yellow and red have the feeling of outward scattering, and vice versa, such as blue and purple have the feeling of inward tightening. (2) The color has a cold feeling, which is proportional to the direction, the warm color is forward, the cold color is backward; the warm color is outward, the cold is introverted. (3) The color has a static and dynamic feeling, the extroversion shows a moving feeling while the introversion is a static feeling. Color techniques have various expressions, so that people can play the psychological role of association. Therefore, in the creation, we should pay attention to the characteristics of colors, and under the principle of highlighting the theme, process the color organically and properly on the screen.

Hegel regards the sense of color in the objective world as a must-have character for the artist. It is impossible to become a painter without this quality. In the composition of SinoRussian Ice-snow Oil Painting art composition, paying attention to color composition, being good at using the change of color tone, and exploring the expression of color are essential for artistry and ideological creating. Color is the most emotional factor in the art creation of Ice-snow Oil Painting. The change of the color in an Ice-snow Oil painting can directly affect people's psychology. In the blue period of Picasso's artistic life, his oil paintings are all silent and lonely 
blue worlds and the people abandoned by the world - patients, the poor, the disabled, the old people. While in his "Rose Red Period", pink became the main theme of his work, and the subject matter of the painting changed from describing the poor to the circus acrobats. The theme of the works of this period is the belief in the goodness of human nature.

In excellent Ice-snow Oil Painting art creation, we can feel the soul and thoughts of the painter from the color. Color can only fully demonstrate its moving power if it is unified with the expression and the human emotions. The color effect of a good Ice-snow Oil painting art work is not arbitrarily painted by the painter. The color composition on the screen is created by the painter with careful configuration. The creation needs both the soul of the painter and the mastery and application of the laws of color are needed. The beauty of form in Ice-snow Oil painting is linked to color. The gripping power and the charm of enlightenment in the art are closely linked to the color effect.

For the Sino-Russian Ice-snow Oil Painting, the analysis and selection of techniques is one of the main issues I have been thinking about and exploring. The techniques in the creation of Ice-snow Oil Painting theme are mainly from the big picture composition, the entry and grasp of the subject relationship, the clear relationship between color and space as well as the use of pen. The artists pay attention to the rhythm of the picture and the change of the melody. The real Ice-snow Oil Painting should have a holistic feeling in variety of shapes, lines and colors. Although the technique is different because of the artist's personality and temperament, the choice of subject matter and performance content, the style of the genre are different and diverse, but we can find several basic techniques in the past Sino-Russian Ice-snow Oil Painting. When people talk about the techniques of Ice-snow Oil Painting, they tend to be easily and simply interpreted as an art form. This may be due to the influence of Western oil painting techniques. The Sino-Russian Ice-snow Oil Painting techniques are the product of the unity of creation content and art form. This is a different view from some schools in the West. In the new era, with the proposal of China's "One Belt, One Road", China and Russia are strengthening cooperation and cultural exchanges in politics, economy, art and other aspects. The research on the similarities and differences between Chinese and Russian Icesnow Oil Painting art has become main subject in the current Chinese and Russian oil painting art creation.

\section{CONCLUSION}

In short, the appeal and expressiveness of the composition techniques of Sino-Russian Ice-snow Oil Painting, in addition to the painter's handling of content and plot, also lies in the use of painting language and various form factors. Studying the past Sino-Russian Ice-snow Oil Painting and our own works, we can understand the various regularities, logic, and basic techniques on composition. Although the painter often underestimates everything he has done, the art theorist has provided us with a correct distinction between the various parts of the painting and the interrelationship, proportion, spatial level and the tone method, which makes us understand why the painter is supposed to be like this. Although the author himself often regards the process of composition as purely intuitive thing, although the process of the artist from conception to concrete expression is often influenced by personal taste, however, in the process of exploring the form and embodying the thought of the artist, it is true that the picture has been changed and constrained by the rules of constitutional structure and developed following a reasonable logic.

\section{REFERENCES}

[1] V. Manin. Russian landscape [M] 200

[2] Smirnov, G. B. Drawing and painting of landscape / G. B. Smirnov [M] L.Vysh. Shk1975.

[3] Shorokhov, V.E. Basics of composition: studies. Allowance zz [M] Enlightenment197.

[4] Chen Luojia.Wai Guo Meishushi Gangyao[M]Southwest normal university press 1995 . (in Chinese)

[5] V.A.melzliakov.Walk through the four seasons of oil painting landscape creation[M]./Guangxi art press 2011

[6] Song Lei. Research on Teaching Methods of Russian Teachers' Oil Painting - Taking Heihe College as an Example, Journal of Heihe University. Volume 7 stage one. 2016. (in Chinese) 